\title{
The challenge to detect and attribute effects of climate change on human and natural systems
}

\author{
Dáithí Stone • Maximilian Auffhammer • Mark Carey • Gerrit Hansen • \\ Christian Huggel • Wolfgang Cramer • David Lobell • Ulf Molau • \\ Andrew Solow · Lourdes Tibig • Gary Yohe
}

Received: 17 February 2013 / Accepted: 14 August 2013 / Published online: 30 August 2013

(C) The Author(s) 2013. This article is published with open access at Springerlink.com

\begin{abstract}
Anthropogenic climate change has triggered impacts on natural and human systems world-wide, yet the formal scientific method of detection and attribution has been only insufficiently described. Detection and attribution of impacts of climate change is a fundamentally cross-disciplinary issue, involving concepts, terms, and standards spanning the varied requirements of the various disciplines. Key problems for current assessments include the limited availability of long-term observations, the limited knowledge on processes and mechanisms involved in changing environmental systems, and the widely different concepts applied in the scientific literature. In order to facilitate current and future assessments, this paper describes the current conceptual framework of the field and outlines a number of conceptual
\end{abstract}

Electronic supplementary material The online version of this article (doi:10.1007/s10584-013-0873-6) contains supplementary material, which is available to authorized users.

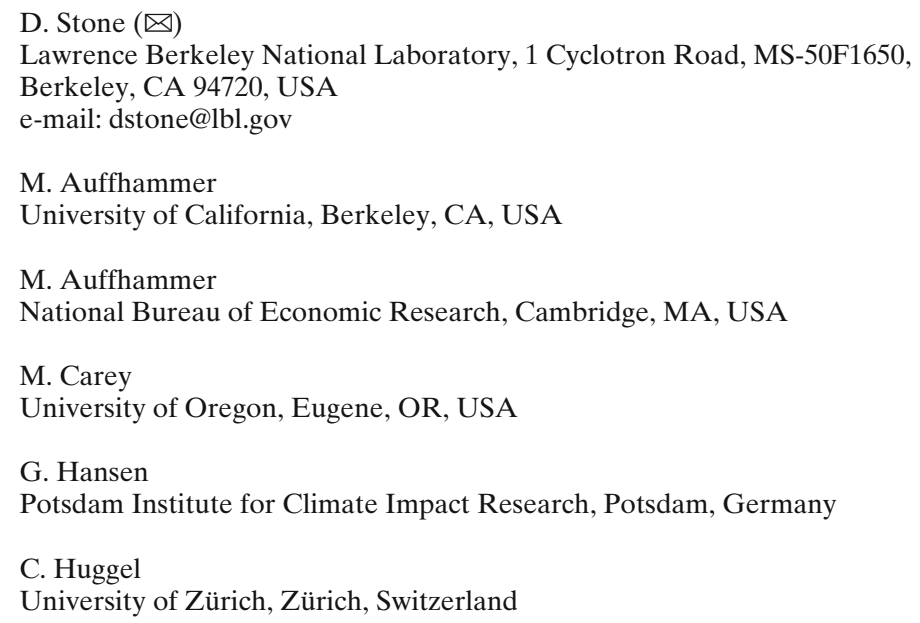


challenges. Based on this, it proposes workable cross-disciplinary definitions, concepts, and standards. The paper is specifically intended to serve as a baseline for continued development of a consistent cross-disciplinary framework that will facilitate integrated assessment of the detection and attribution of climate change impacts.

\section{Introduction}

Anthropogenic climate change has been impacting and continues to impact the environment world-wide (Rosenzweig et al. 2007). Evidence for such effects exists from many natural systems, influenced by increasing temperatures, notably since 1970 . For many other systems, notably human systems, such impacts have been considered to be "... emerging, although many are difficult to discern due to adaptation and nonclimatic drivers" (IPCC 2007).

The rigorous investigation of change in climatic conditions and the detection of an anthropogenic signal in the changing climate have been ongoing for several decades (e.g. Council 1983; Wigley et al. 1990). Only more recently (Smith et al. 2001; Rosenzweig et al. 2007) a similar focus has been developed to formalise the detection and attribution of impacts of climate change on human and natural systems (hereafter "D\&A of impacts" for brevity). The problem of detection and attribution of changing climatic conditions and the D\&A of impacts share important features, but there are also crucial differences. Typically, the assessment demands significant amounts of observations made over periods of several decades-a requirement that is now met for the atmosphere. For impacts, not only are the requirements of observed data more complex and the number of influencing drivers potentially more numerous, but the attribution problem presents additional challenges, including the need to synthesise information from a much broader range of disciplines with differing terminology and types of evidence.

W. Cramer

Mediterranean Institute for Biodiversity and Ecology (IMBE),

Aix-Marseille University/CNRS/IRD/UAPV, Bat. Villemin, Europole de l'Arbois - BP 80,

13545, Aix-en-Provence cedex, France

e-mail: wolfgang.cramer@imbe.fr

D. Lobell

Stanford University, Stanford, CA, USA

U. Molau

University of Gothenburg, Gothenburg, Sweden

A. Solow

Woods Hole Oceanographic Institution, Woods Hole, MA, USA

L. Tibig

The Manila Observatory, Quezon City, Philippines

G. Yohe

Wesleyan University, Middletown, CT, USA 
Substantial stakeholder interest in information concerning the D\&A of impacts is reflected in Article 2 of the UN Framework Convention (UNFCCC), demanding that signatories adopt measures that "prevent dangerous anthropogenic interference with the climate system" (United Nations 1992). While the debate about the exact definition of "dangerous" in the sense of the UNFCCC is on-going, policy-makers and the public have clearly demanded robust information about impacts that have already been observed and might illustrate possible current and future risks to society, thereby creating one of the motivations for the Intergovernmental Panel on Climate Change's (IPCC) Working Group II (WGII) "Impacts, Adaptation and Vulnerability".

Evaluating whether recent climate change (anthropogenic or not) has already caused observable damage requires assessments undertaken within a rigorous D\&A framework. Since impacts concern physical systems (such as rivers and ice-sheets), biological systems (such as forests, grasslands, marine biota), social systems (such as cultural values, governance practices, and livelihoods) and economic systems (such as the production of goods and services), the framework has to cover a wide range of ways to collect and evaluate evidence. Beyond the recognition that frameworks must reflect the criteria established by the different disciplines concerned with the various systems in terms of ways to establish evidence of the existence of impacts, there is also a need for cross-disciplinary standards in order to better understand the collective impacts of climate change. Despite the general acceptance of this need, there has been little structured discussion concerning the fundamentals and how they translate across such a multi-disciplinary and inter-disciplinary field.

In an attempt to start the process of filling this void, this paper is a crossdisciplinary discussion of the history, current state, and challenges in the conceptual framework of the detection and attribution of the effects of climate change on human and natural systems, as well as of possible ways toward a more consistent crossdisciplinary conceptual framework. In particular, we intend to provide a baseline for further discussions, providing:

- a summary of the current conceptual state of the detection and attribution of the impacts of climate change;

- a discussion of specific issues that currently challenge a coherent framework for detection and attribution;

- a set of suggested standards and definitions that address some of these issues;

- a map of a way forward for further addressing these challenges, both at the level of the specific challenges themselves and at the level of the research community.

Essentially, the desired framework is a generalisation of that developed for D\&A of climate change (Hegerl et al. 2007), one that should in fact even be usable outside of the climate change and climate change impacts domains entirely.

\section{Concepts behind detection and attribution}

2.1 Hypothesis-generation, experimental setup, and external drivers

D\&A of impacts evaluates whether aspects of human and natural systems are changing in response to recent climate change. For our initial discussion, it is 
irrelevant whether "recent climate change" is caused by anthropogenic forcings such as greenhouse gas emissions, whether in whole, in part, or not at all-the specific attribution of impacts to anthropogenic climate change will be discussed later in this paper though. A starting point for this discussion is the "Good Practice Guidance Paper" arising from an IPCC Expert Meeting on Detection and Attribution Related to Anthropogenic Climate Change (Hegerl et al. 2010), held in September 2009.

From a systems analytical perspective, the Earth system can be divided into human systems, natural (non-climate) systems, and the climate system (Fig. 1). Each system can be affected by the other two systems (or other external systems) through any number of mechanisms. Hegerl et al. (2010) label all of these mechanisms as external drivers from the point of view of the impacted system, but other terms such as factor, influence, agent, and forcing are also used in various disciplines. Identifying the exact role of these external drivers is the core of D\&A. Natural systems are affected by large numbers of forcings, many of them clearly unrelated to climate change. The term confounding factor is frequently used to refer to this specific class of drivers.

Human activities can affect other systems through drivers of the climate (red arrows in the figure). For instance, emissions of carbon dioxide not only affect the climate but also result in carbon fertilization of land ecosystems and ocean acidification. Humans also affect natural systems in ways completely independent of climate, by anything from hunting through urbanization to water resource management (blue arrows). In turn, natural systems and the climate system may affect each other and/or human systems. While some of these drivers in turn may be a direct response to an anthropogenic driver of climate change (dashed red arrows), for instance the warming of the climate in response to anthropogenic emissions, others are unrelated to anthropogenic climate change (blue arrows in the figure). Finally, there are drivers which can be considered completely external to these three systems which can affect the climate (grey arrow), such as volcanic eruptions and variations in the solar luminosity.

To perform a detection and attribution analysis one conceptually tries to isolate the system of interest (illustrated by the shaded circles in the figure), in which case all of the incoming drivers can be considered external for the purpose of the study. The analysis then involves examining how the observed behaviour of the system compares against what would be expected if various drivers were removed. Detection and attribution studies of the physical climate system are represented by the magnifying glass over the climate system and the isolation of the climate system from everything else, as depicted by the grey circle. D\&A of impacts of climate change essentially considers most of the remaining permutations, which in the figure include the magnifying glasses over the natural and human systems.

\subsection{Models}

The description above illustrates the experimental challenge in detection and attribution studies. We cannot perform randomised controlled experiments using multiple Earths. Instead, the studies must be performed using conceptual models of the various systems (Sparks and Tryjanowski 2005). While the term model can have a very specific and narrow definition or connotation within disciplines (e.g. for the physical 


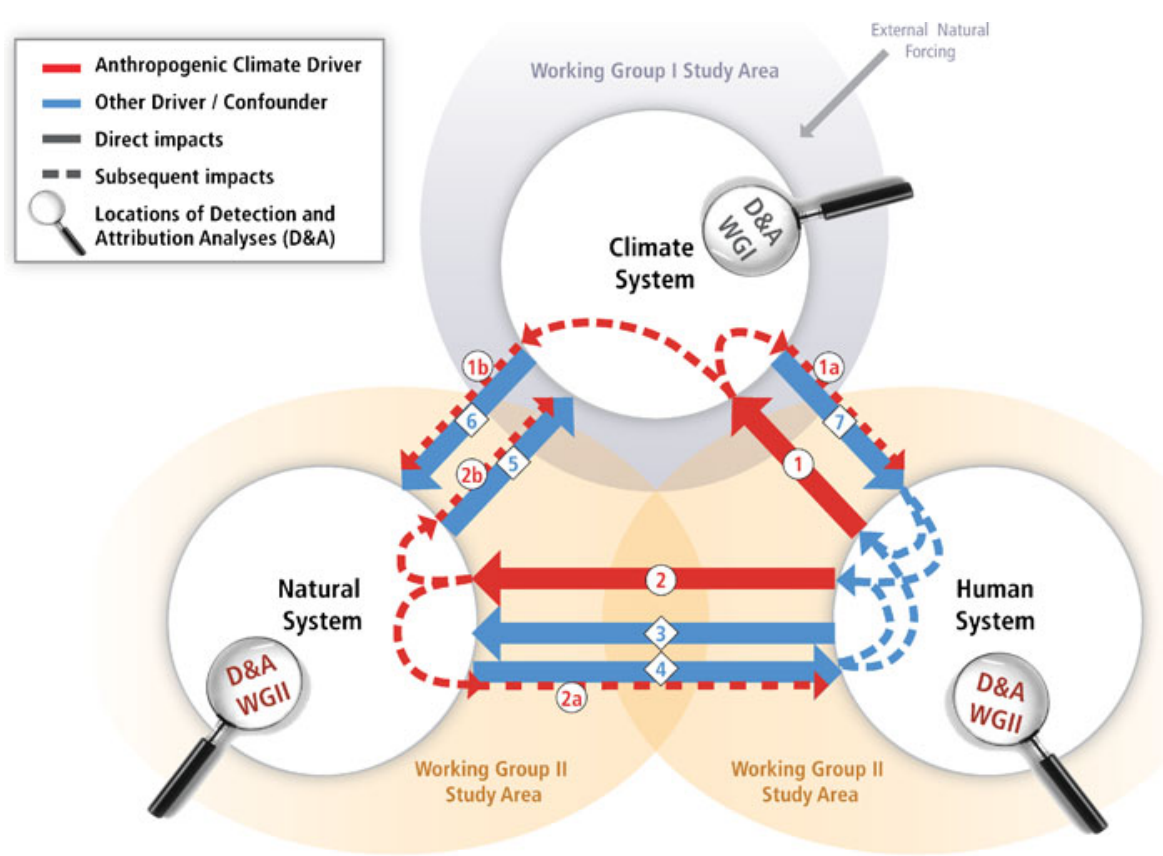

\begin{tabular}{c|l|l|l}
\hline \multirow{2}{*}{} & \multirow{2}{*}{ Example of Drivers } & \multicolumn{2}{|c}{ Example of Impacts } \\
\cline { 3 - 4 } & & Direct impacts & Subsequent impacts \\
\hline 1 & Emission of $\mathrm{CO}_{2}$ & Warming & Altered crop yield \\
$1 \mathrm{a}$ & & & Shift in species phenology \\
\hline $\mathrm{b}$ & & Carbon fertilization of plants & Increase in forestry yield \\
\hline 2 & Emission of $\mathrm{CO}_{2}$ & & \\
$2 \mathrm{a}$ & & & \\
\hline $\mathrm{b}$ & & Change in humidity \\
\hline 3 & Pollution of river catchment & Decrease in fisheries & \\
\hline 4 & Plague of crop pests & Decrease in crop yield & \\
\hline 5 & Forest fire & Increased windiness & \\
\hline 6 & El Nino event & More wildfires & \\
\hline 7 & El Nino event & Fisheries & \\
\hline
\end{tabular}

Fig. 1 A schematic of the interactions in the world as viewed in detection and attribution analysis. For the given illustrative purpose, the Earth system is divided into three broads systems that interact through various natural and anthropogenic interactions (blue and red arrows), including anthropogenic drivers of climate change (red arrows). Impacts of anthropogenic climate drivers can in turn affect other systems (dashed red arrows). In detection and attribution studies the experimental setup considers one of the shaded bubbles, analysing how changes in the various external drivers (arrows) affect the behaviour of the system (magnifying glasses). Examples of drivers and their impacts are given in the table

climate see Hegerl and Zwiers 2011) here we take it in its broadest sense, as a construct that interprets our understanding of the system into a behavioural outcome.

On the one extreme, models can be mechanistic or conceptual, representing the system through a chain of logical arguments based on understanding of the processes that together comprise the mechanics of the system. In some cases it is possible and 
feasible to represent these logical arguments numerically (Hegerl and Zwiers 2011). Models may also be derived empirically, relating the response of a system to external drivers according to relationships estimated through observations, experimentation, or survey. This approach is common in the qualitative social sciences, where social relations, power structures, institutions, economics, and cultural beliefs can intersect with external drivers in complicated ways too difficult to model mechanistically. In practice, modelling setups will almost always use a combination of mechanistic and empirical components (e.g. Rodó et al. 2013; Zwiers and von Storch 2004): mechanistic hydrological models nevertheless represent small-scale processes through largely empirical means, for instance, while the selection of the institutions and beliefs to consider in an empirical study of the effects of climate change on societies will have involved some mechanistic understanding of what might be worthy of investigation (Ruddell et al. 2012; Howe et al. 2012).

Much recent discussion of D\&A of impacts has focused on quantitative analyses (e.g. Rosenzweig et al. 2007), but in doing so has neglected a substantial fraction of the research in the social sciences and humanities that is qualitative in nature. During the past two decades social sciences and humanities have developed their own approaches through concepts that recognise fluid interactions and blurry boundaries between human systems and natural systems, such as with approaches based in socialecological systems, coupled natural and human systems, actor network theory, and hybrid landscapes. These approaches are generally built on complex systems theory and identify dynamic interactions and feedbacks among an assemblage of intersecting forces in these systems. They point to internal and external variables (or drivers) that vary across time and space. These variables are diverse and include demography, land use, resource use and management, settlement patterns, governance structures, policies, legislation, institutions, social relations, economic motives and practices, worldviews, cultural values, knowledge systems, technologies, and environmental forces. For example, the influence of climate change on human migration is mediated by other socio-economic factors such as education levels, income variability, access to health care and remittances. This body of social science research thus emphasises the qualitative analysis of multiple, intersecting "impact chains" that often integrate drivers, with climate change identified as one among many others.

\subsection{Confidence assessment}

Inevitably, detection and attribution studies rely on the analysis of observations. Many of these analyses are explicitly statistical in nature, using signal detection methods in time series data, but other analyses are qualitative. Qualitative analyses incorporate a broader evaluation of research results to determine the quality of sources and data, the number of sources and amount of data, the diversity of data sources to reduce particular biases, and the corroboration of empirical evidence through diverse and numerous sources. It is important to distinguish the quantitative/qualitative distinction for analysis of confidence from the modelling setup discussed above. Quantitative modelling allows both quantitative and qualitative statements of confidence. On the other hand, if a modelling framework lacks a numerical formulation or uses a highly simplified numerical formulation then confidence assessments must be qualitative. In IPCC assessments, quantitative assessments are being expressed using 
either the likelihood or confidence metrics of Mastrandrea et al. (2010), as appropriate, while the confidence metric is appropriate for the qualitative assessments.

\section{Detection}

\subsection{Past concepts of detection}

The concept of detection in the context of climate change has evolved considerably through time, as can be monitored through the IPCC literature (Supp. Table 1). The definition used by IPCC Working Group I (dealing with physical climate change) in the First Assessment Report (Wigley et al. 1990) resembles the contemporary concept of attribution (see definitions of attribution in Supp. Table 2), with a more contemporary definition, separate from attribution, appearing in the Second Assessment Report (Santer et al. 1996). For IPCC WGII (dealing with the impacts of climate change on human and natural systems) detection was not specifically defined until the Fourth Assessment Report (Rosenzweig et al. 2007), and in this case was considered inseparable from attribution. The first appearance in IPCC WGII literature of a concept of detection distinct from attribution was in Hegerl et al. (2010), which essentially adopted the definition from IPCC WGI (Hegerl et al. 2007).

\subsection{The reference for detection}

The detection of climate change, without attribution of causes, provides the baseline against which hypotheses of any anthropogenic component of climate change can be compared. When it comes to the impacts of climate change, interpreting baseline detection of change becomes a very complex matter, due to the multiple changes in the global environment, including human society itself (e.g. Bouwer 2011). Many human systems (e.g. the economy) and natural systems (e.g. species ranges) would be changing in the absence of climate change- this is their plausible or expected state and due to the impact of drivers other than climate change and in some cases the unstable nature of the system itself.

For impacts, we propose to adjust the definition in a way that takes into account this complexity. It must reflect the variability of the impacted system, even when this variability is not known in all its finesse. We therefore suggest that, for impacted systems, detection addresses the question of whether a system is changing beyond a specified baseline that characterizes behaviour in the absence of climate change. The behavioural baseline can be set appropriately for any system being studied (e.g. Newman et al. 2009).

\subsection{Spatial and temporal scales}

Any detection study must be clear about the scales in space and time analyzed (Root and Schneider 2003; Sparks and Tryjanowski 2005). Many natural and human systems lack links between local, regional, and global scales. Non-climatic drivers of change may also act over different scales, and local and regional scales often intermix with national and global forces. Effects of drivers on, for instance, agriculture, 
forestry and fisheries depend on the type of production system, which can differ quite significantly across different countries and regions. At the same time, international drivers of change such as trade, commodity and resource production, and politicaleconomic forces like colonialism or neoliberal economic policies act on global scales but play out within distinct local, regional, and national settings.

A frequent characteristic of impacted systems is their delayed response to climatic changes (Ahmad et al. 2001). The magnitude of this time lag may vary among different impacted systems and within them, from seconds or minutes to centuries or millennia (for examples see Supp. Table 3).

\subsection{Adaptation}

Besides natural and intrinsic variability, a further issue for detection studies is how to consider autonomous and planned adaptation (Rosenzweig and Neofotis 2003; Schneider et al. 2000). In fact, the degree of adaptation per se can be an indicator of change. Some of the highest confidence conclusions in D\&A of impacts have concerned the poleward movement of species or shifts in their phenology (Parmesan and Yohe 2003; Root et al. 2003, 2005): these are simply adaptative measures taken by the organisms in response to changes in their environment. The adaptive capacity of systems can thus be extremely relevant for detection analysis. The interpretation is more ambiguous with human systems however. Depending on their adaptive capacity, people may also autonomously adapt to climate changes. In systems where the precautionary principle is followed, for instance in health, any hint of detection can trigger measures to reduce exposure and/or vulnerability, with the implicit intention of removing any response signal (Carson et al. 2006). Detection is still possible if the effects of the adaptation measures are well understood and they do not completely remove the response to climate change, but any adaptation is a serious confounding factor when it comes to detection analysis (Holland and Smit 2010).

Furthermore, human systems have the capacity for planned adaptation, using understanding of expected future impacts to ensure that they do not in fact unfold. In this setting, the perception of likely impacts can matter immensely. Understanding of past impacts may reflect both real and perceived impacts, while the expectation of future impacts rests within the context of other expectations about the future. Different people, groups, and stakeholders can detect—or believe they detect—climate change in distinct ways. Thus their real or perceived detection can in turn trigger responses which result in impacts.

\section{Attribution}

\subsection{The concept of attribution}

The overlying trend in the IPCC's evolving definition of attribution has been toward increasing the distinction of the specific procedural steps from a more generic conceptualization (Supp. Table 2). Within the IPCC WGI Assessment Reports, attribution only started to become a separate concept from detection in Santer et al. (1996). By the time of Hegerl et al. (2010) the core of the attribution definition 
no longer referred to detection or to methods. Similarly within the IPCC WGII publications, the definition in Rosenzweig et al. (2007) was procedural, while the Hegerl et al. (2010) definition was conceptual.

Within the setting of the D\&A of impacts, attribution is distinguished from detection mainly in its assessment of the magnitude of the contribution of climate. So while detection addresses whether a system is changing beyond some reference behaviour, attribution addresses the question of whether climate change has contributed substantially to the observed change in a system. Any assessment of attribution thus requires a description of the magnitude considered, with an assessment of a minor role (a small contribution relative to other drivers of the detected change) being different from the assessment of a major role (one of the main drivers of the detected change), for instance.

The term attribution suffers from being a commonly used term with rather different meanings across the many disciplines involved in assessing the impacts of climate change. For instance, attribution theory is a major area of social psychology (Rudolph and Reisenzein 2008), but the aim of an attribution study "is not to determine the true causes of ... an event but rather to understand people's perceptions of causality" (Kassin et al. 2008). Thus in interdisciplinary studies it is important to specify the definition for clarity.

\subsection{The attribution end points}

A common point of confusion is a lack of clarity about the end points of attribution analyses (Hegerl et al. 2010). The most frequently observed attribution statement is one where a human or natural system has changed in response to observed climate change, where climate change is any consistent long term trend in a climate variable (no matter what the cause). The detected and attributable change is not limited to changes in the means of climate variables but could be due for instance to changes in the frequency of extremes.

A second, more challenging, end point is attribution to anthropogenic climate change, i.e. to anthropogenic climate drivers. Climate change consists of the combination of responses to anthropogenic forcings of climate change (e.g. greenhouse gas concentrations, land use change), responses to natural forcings (e.g. explosive volcanic eruptions), and natural unforced fluctuations in the climate. Thus attribution to climate change is not equivalent to attribution to anthropogenic climate change: going from the former to the latter requires the decomposition of the observed climate change into the various components.

D\&A is straightforward to conceptualise when the impacts of various drivers are additive, that is if they add linearly to produce the cumulative observed change. Assessment of the magnitude of the climate change contribution is nuanced however when the impact of climate change is modified through the presence of another driver. For instance while an increased frequency of heat waves may have resulted in a large excess mortality, it may also have been within the context of a slow responsiveness of health services, which themselves depend on economic constraints, cultural norms, and legislation (Lalande et al. 2003). Thus, discussion of the sensitivity to the ceteris paribus assumption should be considered a vital component of D\&A of impacts studies. 


\subsection{Methodological approaches}

There have been a large number of terms used within the D\&A of impacts literature to classify different types of methodological approaches to attribution (e.g. Hegerl et al. 2010; Rosenzweig et al. 2007; Stone et al. 2009), with little standardization across disciplines. With concern over how a large taxonomy may lead to confusion, Hegerl et al. (2010) proposed a small harmonised set of categories.

The major distinction is between single-step and multi-step approaches (Fig. 2). The single-step approach uses a single modelling setup to relate changes in drivers to changes in some aspect of a climate, natural, or human system. A multi-step approach, on the other hand, links separate single-step approaches into an overall attribution assessment. For instance, one single-step analysis may relate the retreat of a particular European glacier to local summer warming, while another single-step analysis might relate annual warming over Europe to anthropogenic emissions. A multi-step analysis would combine these two studies into an assessment of the impact of anthropogenic emissions on that glacier. By contrast, a single-step approach for the full assessment would have used a modelling setup that had a glacial model responding directly to the local high-frequency output of a climate model driven

\section{Single-step approach}

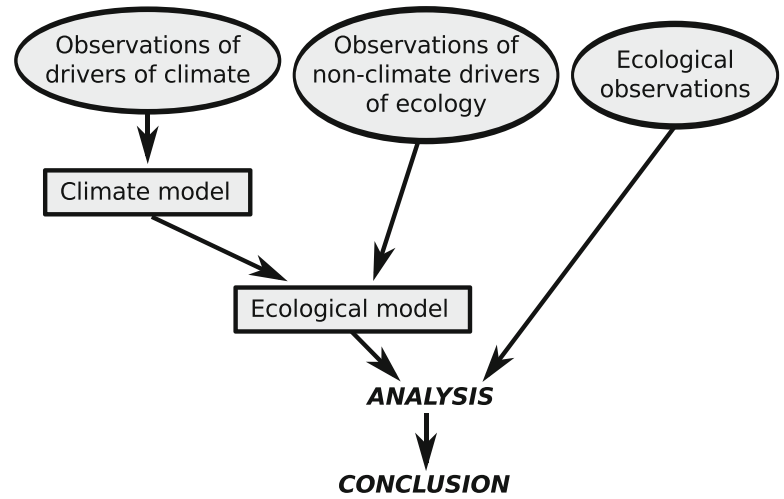

Multi-step approach

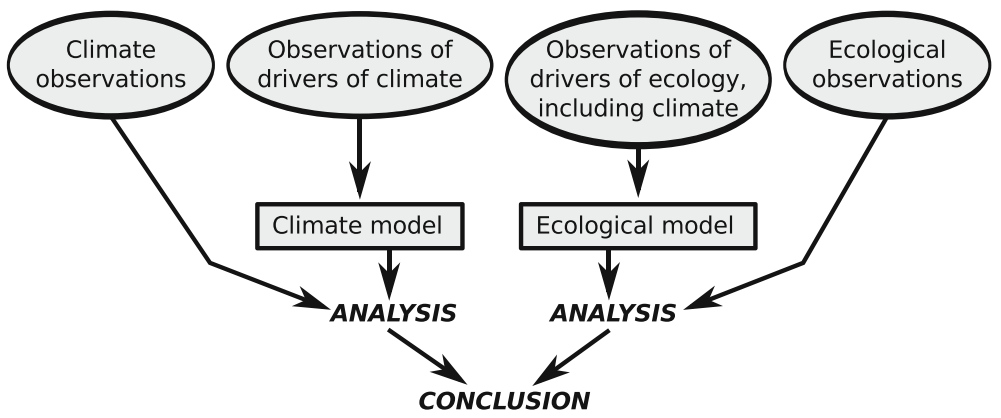

Fig. 2 Schematic of the procedures behind single-step and multi-step (here two-step) approaches to attribution for the case study of an ecological system. 
by anthropogenic emissions (Reichert et al. 2002; Mölg et al. 2012). The difference is that the multi-step approach includes a logical disconnect, in the example above relating annual continental warming to seasonal local warming. However, any singlestep modelling framework will also have some approximations made at the various interfaces between different components of the models as well as between system models, so the distinction involves an informed judgment as to whether the disconnects that exist could reasonably matter, rather than being a fundamental property of the experimental setup.

At face value, the single-step approach might be expected to be more appropriate, but this is not necessarily the case. A single-step approach might involve a modelling setup that is technologically impractical without resorting to highly simple models, while more complex models can be used with a multi-step approach (Pall et al. 2011). Additionally, it may be difficult to link qualitative and quantitative models in a singlestep approach.

\subsection{Synthesis assessments}

Hegerl et al. (2010) also identified an associative pattern approach to attribution as the "synthesis of large numbers of results ... using spatial and temporal measures of association" (which, nevertheless, would still need to be carried out through a single- or multi-step approach). The intention of this category was to cover syntheses across different systems, for instance across multiple species. For these synthesis assessments, confidence in conclusions concerning individual results must be combined into one overarching assessment of confidence (Ahmad et al. 2001). One way, championed by ecologists (Parmesan and Yohe 2003; Root et al. 2003, 2005; Rosenzweig et al. 2008), is through meta-analysis of the existing literature, testing for changes consistent with warming and discussing (and perhaps excluding) potential contributions from other drivers (Rosenzweig and Neofotis 2003). In the case of Rosenzweig et al. (2008) the spatial pattern of results of a meta-analysis was correlated with the actual pattern of observed warming. Formally, meta-analyses can allow for covariability of errors and natural variability across studies, but the assumption is required that these will cancel out given a large enough sample of studies (Hockey et al. 2011; Parmesan et al. 2011; Rosenzweig and Neofotis 2003; Zwiers and Hegerl 2008).

Associative pattern approaches have restrictions on the type of information that can be input, most particularly in that the information must come from studies of similar formats. This excludes information from research that does not fit neatly into formal "detection" or "attribution" analysis yet that is relevant to D\&A assessment. It is difficult, for instance, to see how qualitative social science conclusions can be incorporated into the various existing associative pattern methods. In order to obtain a more complete synthesis, therefore, future approaches will need to be able to incorporate information beyond the subclass of prototypical D\&A studies.

In general, confidence in attribution in a synthesis assessment depends on the quality, coverage, and independence of the various input studies, their agreement, and the confidence in the individual attribution assessments. One common temptation in synthesis assessments is to go for the least common denominator, by simply assigning the lowest confidence level of any single study included in the synthesis (Rosenzweig and Neofotis 2003), while another option is to take the "middle" study, essentially averaging the confidence assessments of the individual studies. But these 
assessments of confidence are generally inappropriate: for instance, taken to the extreme they would require consideration of the myriad systems for which there is a lack of evidence for the existence of climate-induced change. The confidence in a synthesis assessment depends on the nature of the evidence of the individual studies and on their agreement. For instance, aggregation may lead to higher overall confidence if there is strong agreement between the individual studies (Parmesan et al. 2011), but this would not be the case if agreement is weak.

\section{The way forward}

A number of challenges in the D\&A of impacts have been noted in this paper, both at the level of individual studies and when synthesizing across studies. But it has not been possible to address all issues. The issue of how to consider D\&A within a risk-based framework was not treated head-on, for instance, with the risk-related discussion instead focusing on component issues, such as the role of adaptation. The treatment of extreme events from an impacts perspective (e.g. loss and damage) was not discussed at all, but in this case there is already an active discussion (e.g. Bouwer 2011; Huggel et al. 2013).

The number of studies analyzing the D\&A of impacts is growing markedly. With this growth, many standards, including terminology, definitions, and methods, will develop naturally as each study places itself within the context of its predecessors. However, with such a multi-disciplinary topic there is a strong possibility that this will lead to many isolated sets of standards, with one for each discipline. To some degree that may be an advantage, inasmuch as the conclusions of these studies are considered within disciplinary decision-making bodies with compatible standards. However, the existence of multiple concepts and standards will pose a major problem for informing decisions with consequences across human and natural systems. Moreover, this natural development of concepts and standards may occur only over a relatively long period.

As evidenced by Rosenzweig and Neofotis (2003) and Hegerl et al. (2010), the IPCC assessment process has provided a helpful forum for discussing and developing concepts and standards for D\&A of impacts. This opportunity waxes and wanes with the IPCC assessment cycle, however, and in any case it is not intended or designed to provide a workshop environment conducive to conceptual discussion. Considering this, we argue that there is a need for a venue explicitly designed for voluntary and sustained multi-disciplinary discussion of the concepts, standards, and methods behind the D\&A of impacts. One possible model would be an impacts mirror of IDAG (the International ad hoc Detection and Attribution Group), a voluntary group discussing the theory and practice of the D\&A of physical climate change for two decades (IDAG 2005). Specific topics are already being addressed in some other fora, for instance extreme events within the Attribution of Climaterelated Events activity (Stott and Trenberth 2009, ACE). But a broader venue, interacting with ACE and other activities, would provide a vital cross-disciplinary opportunity to not only evaluate and discuss the sorts of issues raised in this paper, but to propose concepts and methods which fit within various disciplinary frameworks and match the discussions of the more focused fora. Whatever the venue, some particular tasks would be the development of protocols for defining 
the "behavioural baseline" for detection analysis, the setting of workable crossdisciplinary standards for assessing the confidence in D\&A results, and the development of a framework for assessing the D\&A of risk (including extreme impact events), as well as discussion concerning how D\&A assessments can better address the needs of society and decision-makers. More attention to the specifics of the D\&A of impacts among climate change researchers in general would help refine climate change studies, sharpen awareness about actual changes taking place (and the drivers of those changes), illuminate the best areas and approaches for effective adaptation, and expand understanding of how coupled natural and human systems work.

Acknowledgements We thank the Detection and Attribution Liaisons to IPCC AR5 WGII Chapter 18, Chris Field, and Mike Mastrandrea for many helpful discussions. We are also grateful to Yuka Estrada and Monalisa Chatterjee for assistance in graphic design. While the chapter authors are all members of the AR5 Chapter 18 author team, all opinions, findings, and errors are those of the authors alone. Many of the discussions distilled here were conducted during and around Lead Author Meetings of the IPCC assessment process, supported by various national governments. DS was supported by the Regional and Global Climate Modeling Program and the Earth System Modeling Program of the Office of Biological and Environmental Research in the Department of Energy Office of Science under contract number DE-AC02-05CH11231. GH was supported by a grant from the German Ministry for Education and Research.

Open Access This article is distributed under the terms of the Creative Commons Attribution License which permits any use, distribution, and reproduction in any medium, provided the original author(s) and the source are credited.

\section{References}

Ahmad QK, Warrick RA et al (2001) Methods and tools. In: McCarthy JJ, Canziani OF, Leary NA, Dokken DJ, White KS (eds) Climate change 2001. Impacts, adaptation, and vulnerability. Cambridge University Press, Cambridge, pp 105-143

Bouwer LM (2011) Have disaster losses increased due to anthropogenic climate change? Bull Amer Meteor Soc 92:39-46

Carson C, Hajat S, Armstrong B, Wilkinson P (2006) Declining vulnerability to temperature-related mortality in London over the 20th century. Am J Epidemiol 164:77-84. doi:10.1093/aje/kwj147

Council NR (1983) Changing climate: report of the Carbon Dioxide Assessment Committee. Board on Atmospheric Sciences and Climate, National Academy Press, Washington, 496pp

Hegerl G, Zwiers F (2011) Use of models in detection and attribution of climate change. WIREs Climate Change 2:570-591

Hegerl GC, Zwiers FW, Braconnot P, Gillett NP, Luo Y, Marengo Orsini JA, Nicholls N, Penner JE, Stott PA et al (2007) Understanding and attributing climate change. In: Solomon S, Qin D, Manning M, Chen Z, Marquis M, Averyt KB, Tignor M, Miller HL (eds) Climate change 2007: the physical science basis. Contribution of working group I to the fourth assessment report of the intergovernmental panel on climate change. Cambridge University Press, Cambridge, pp 663-745

Hegerl GC, Hoegh-Guldberg O, Casassa G, Hoerling MP, Kovats RS, Parmesan C, Pierce DW, Stott PA (2010) Good practice guidance paper on detection and attribution related to anthropogenic climate change. In: Stocker TF, Field CB, Qin D, Barros V, Plattner GK, Tignor M, Midgley PM, Ebi KL (eds) Meeting report of the intergovernmental panel on climate change expert meeting on detection and attribution of anthropogenic climate change. IPCC Working Group I Technical Support Unit, University of Bern, Bern

Hockey PAR, Sirami C, Ridley AR, Midgley GF, Babiker HA (2011) Interrogating recent range changes in South African birds: confounding signals from land use and climate change present a challenge for attribution. Diversity Distrib 17:254-261 
Holland T, Smit B (2010) Climate change and the wine industry: current research themes and new directions. J Wine Res 21:125-136. doi:10.1080/09571264.2010.530095

Howe PD, Markowitz EM, Lee TM, C-Y K, Leiserowitz A (2012) Global perceptions of local temperature change. Nat Clim Change 3:352-356. doi:10.1038/nclimate1768

Huggel C, Stone D, Auffhammer M, Hansen G (2013) Loss and damage attribution. Nat Clim Change 3:694-696

IDAG (2005) Detecting and attributing external influences on the climate system: a review of recent advances. J Climate 18:1291-1314

IPCC (2007) Summary for policymakers. In: Parry ML, Canziani OF, Palutikof JP, van der Linden PJ, Hanson CE (eds) Climate change 2007: impacts, adaptation and vulnerability. Contribution of working group II to the fourth assessment report of the intergovernmental panel on climate change. Cambridge University Press, Cambridge, pp 7-22

Kassin S, Fein S, Markus HR (2008) Social psychology, 8th edn. Wadsworth, Belmont, CA, 620pp

Lalande F, Legrain S, Valleron AJ, Meyniel D (2003) Mission d'expertise et d'évaluation du système de santé pendant la canicule 2003. Tech. rep., Ministère de la santé, de la famille, et des personnes handicapées, Paris, France, http://lesrapports.ladocumentationfrancaise.fr/BRP/ 034000558/0000.pdf. Accessed 30 Jan 2013

Mastrandrea MD, Field CB, Stocker TF, Edenhofer O, Ebi KL, Frame DJ, Held H, Kriegler E, Mach KJ, Matschoss PR, Plattner GK, Yohe GW, Zwiers FW (2010) Guidance note for lead authors of the IPCC fifth assessment report on consistent treatment of uncertainties. Intergovernmental Panel on Climate Change (IPCC). Available at http://www.ipcc.ch

Mölg T, Groß hauser M, Hemp A, Hofer M, Marzeion B (2012) Limited forcing of glacier loss through land-cover change on Kilimanjaro. Nat Clim Change 2:254-258. doi:10.1038/ nclimate 1390

Newman PA, Oman LD, Douglass AR, Fleming EL, Frith SM, Hurwitz MM, Kawa SR, Jackman CH, Krotkov NA, Nash ER, Nielsen JE, Pawson S, Stolarski RS, Velders GJM (2009) What would have happened to the ozone layer if chlorofluorocarons (CFCs) had not been regulated? Atmos Chem Phys 9:2113-2128

Pall P, Aina T, Stone DA, Stott PA, Nozawa T, Hilberts AGJ, Lohmann D, Allen MR (2011) Anthropogenic greenhouse gas contribution to flood risk in England and Wales in autumn 2000. Nature 470:382-385

Parmesan C, Yohe G (2003) A globally coherent fingerprint of climate change impacts across natural systems. Nature 421:37-42

Parmesan C, Duarte C, Poloczanska E, Richardson AJ, Singer MC (2011) Overstretching attribution. Nat Clim Change 1:2-4

Reichert BK, Bengtsson L, Oerlemans J (2002) Recent glacier retreat exceeds internal variability. J Clim 15:3069-3081

Rodó X, Pascual M, Doblas-Reyes FJ, Gershunov A, Stone DA, Giorgi F, Hudson PJ, Kinter J, Rodríguez-Aria MA, Stenseth NC, Alonso D, García-Serrano J, Dobson AP (2013) Climate change and infectious diseases: can we meet the needs for better prediction? Climate Change 118:625-640

Root TL, Schneider SH (2003) Strategic cyclical scaling: bridging five orders of magnitude scale gaps in climatic and ecological studies. In: Rotmans J, Rothman DS (eds) Scaling issues in integrated assessment. Swets and Zeitlinger Publishers, pp 179-204

Root TL, Price JT, Hall KR, Schneider SH, Rosenzweig C, Pounds A (2003) Fingerprints of global warming on wild animals and plants. Nature 421:57-60

Root TL, MacMynowski DP, Mastrandrea MD, Schneider SH (2005) Human-modified temperatures induce species changes: joint attribution. Proc Natl Acad Sci 102:7465-7469

Rosenzweig C, Neofotis PG (eds) (2003) IPCC workshop report on the detection and attribution of the effects of climate change. NASA/Goddard Institute for Space Studies, New York, 87pp

Rosenzweig C, Casassa G, Karoly DJ, Imeson A, Liu C, Menzel A, Rawlins S, Root TL, Seguin B, Tryjanowski P et al (2007) Assessment of observed changes and responses in natural and managed systems. In: Parry ML, Canziani OF, Palutikof JP, van der Linden PJ, Hanson CE (eds) Climate change 2007: impacts, adaptation and vulnerability. Contribution of working group II to the fourth assessment report of the intergovernmental panel on climate change. Cambridge University Press, Cambridge, UK, pp 79-131

Rosenzweig C, Karoly D, Vicarelli M, Neofotis P, Wu Q, Casassa G, Menzel A, Root TL, Estrella N, Seguin B, Tryjanowski P, Liu C, Rawlins S, Imeson A (2008) Attributing physical and biological impacts to anthropogenic climate change. Nature 453:353-357 
Ruddell D, Harlan SL, Grossman-Clarke S, Chowell G (2012) Scales of perception: public awareness of regional and neighborhood climates. Climate Change 111:581-607. doi:10.1007/s10584011-0165-y

Rudolph U, Reisenzein R (2008) 50 years of attribution research. Soc Psychol 39:123-124

Santer BD, Wigley TML, Barnett TP, Anyamba E et al (1996) Detection of climate change and attribution of causes. In: Houghton JT, Meira Filho LG, Callander BA, Harris N, Kattenberg A, Maskell K (eds) Climate change 1995: the science of climate change. Contribution of working group I to the second assessment report of the intergovernmental panel on climate change. Cambridge University Press, Cambridge, UK, pp 407-443

Schneider SH, Easterling WE, Mearns LO (2000) Adaptation: sensitivity to natural variability, agent assumptions and dynamical climate changes. Climatic Change 45:203-221

Smith JB, Schellnhuber HJ, Qader Mirza MM et al (2001) Vulnerability to climate change and reasons for concern: a synthesis. In: McCarthy JJ, Canziani OF, Leary NA, Dokken DJ, White KS (eds) Climate change 2001. Impacts, adaptation, and vulnerability. Cambridge University Press, Cambridge, UK, pp 913-967

Sparks TH, Tryjanowski P (2005) The detection of climate impacts: some methodological considerations. Int J Climatol 25:271-277

Stone DA, Allen MR, Stott PA, Pall P, Min SK, Nozawa T, Yukimoto S (2009) The detection and attribution of human influence on climate. Annu Rev Environ Resour 34:1-16

Stott P, Trenberth K (2009) Linking extreme weather to climate variability and change. Eos 90:184

United Nations (1992) United Nations framework convention on climate change. FCCC/ INFORMAL/84, http://unfccc.int/essential_background/convention/background/items/1349.php

Wigley TML, Barnett TP et al (1990) Detection of the greenhouse effect in the observations. In: Houghton JT, Jenkins GJ, Ephraums JJ (eds) Climate change. The IPCC scientific assessment. Cambridge University Press, Cambridge, UK, pp 241-255

Zwiers F, Hegerl G (2008) Attributing cause and effect. Nature 453:296-297

Zwiers FW, von Storch H (2004) On the role of statistics in climate research. Int J Climatol 24:665-680 